\title{
Tubed Adipofascial Radial Artery Perforator Flap for Recurrent and Persistent Carpal Tunnel Syndrome
}

\author{
TAREK ZAHRA, M.D. and AHMED M. ZEINA, M.D. \\ The Department of Plastic and Reconstructive Surgery, Faculty of Medicine, Mansoura University
}

\begin{abstract}
Background: Recurrence of the symptoms of median nerve entrapment over the wrist remains a challenging problem and in most cases it is secondary to recurrent adhesions around the median nerve, vascularized tissue coverage is one of the most successful treatments to relieve pain and prevent recurrence.
\end{abstract}

Material and Methods: Fifteen patients were involved in this study with recurrent or persistent carpal tunnel syndrome to study benefit of vascularized wrapping of median nerve by tubed adipofascial radial artery perforator flap.

Results: Marked improvement had been observed in nerve conduction studies, visual analogue scale and grip strength with no recurrence for one year postoperatively.

Conclusion: Radial artery perforator adipofascial flap have the advantage of good volume and vascularity providing protection and vascular supply to the severed median nerve.

Key Words: Carpal tunnel - Radial artery perforator flap Adipofascial flap - Median nerve - Entrapment syndromes - Perforator flap.

\section{INTRODUCTION}

Chronic median nerve injuries represent a major clinical problem associated with unpredictable final outcome and multiple manifestations especially pain. The problem can be presented even after median nerve repair, carpal tunnel release or untreated median nerve injury [1].

Persistence of symptoms or recurrence of carpal tunnel syndrome (CTS) is frequent after surgical treatment soft tissue adhesions to the nerve, interstitial scar, and epineurial fibrosis are common causes of the recurrent CTS. Many treatments had been described well in literature; the aim of treatments was to improve quality of life by minimizing pain with maintenance of median nerve function.
Neurolysis is often the first attempt, but it does not always relieve the pain $[\mathbf{1 , 2}]$.

Reconstruction by vascularized tissue coverage had been described for treatment of chronic pain associated with median nerve injury. Authors described coverage by pedicled flaps or free flaps, all techniques of coverage to allow smooth gliding coverage, prevent adhesion, minimize scaring and protect nerve from trauma $[2,3]$.

One of most successful treatment is use of adipofascial radial artery perforator flap. The flap is a good choice for treatment of chronic pain associated with median nerve injury. The flap is supplied by the septocutaneous perforators of the radial artery which emerges in the distal forearm in the septum between the flexor carpi radialis and the brachioradialis tendons [1,4]. The flap gives about ten small perforating vessels with diameters between 0.3 and $0.9 \mathrm{~mm}[\mathbf{5 , 6 , 7 ]}$. These vessels arise approximately $1.5 \mathrm{~cm}$ proximally to the radial styloid and proximally at intervals of 0.4 to $1.5 \mathrm{~cm}$ [8]. A rich venous plexus accompanies this arterial network. The cadaveric studies for the anatomy of radial artery perforator in the distal forearm resulted in finding 2-3 significant perforators within $2 \mathrm{~cm}$ from the radial styloid process in majority of cases [9-12].

This study was conducted to study benefit of vascularized wrapping of median nerve by adipofascial radial artery perforator flap.

\section{PATIENTS AND METHODS}

This prospective study was conducted from august, 2015 to March, 2017 after approval of Institutional Review Board (IRB) of Mansoura 
Faculty of Medicine (code no. R/16.06.51). Written informed consents were obtained from 15 patients with recurrent or persistent pain and numbness over the area of distribution of the median nerve lasting for six months after carpal tunnel release. Patient with chronic debilitating disease, trauma to the radial artery and patients with other neurological deficit were excluded from the study.

Proper history was taken, nerve examination was done, Nerve conduction velocity and electromyography was done and 2 point discrimination to the index finger was recorded. Patients were asked to score their pain according to visual analogue pain score and to answer the disabilities of the arm, shoulder and hand score (quick DASH) [21].

Hand held Doppler ultrasound was used to roughly locate the perforator but it was difficult in most cases to distinguish between the artery and the perforator, general Anesthesia was used in all patients. The arm was exanguated by gravity and tourniquet inflated and the arm is fully extended on side table (Fig. A1).

First, Incising the ulnar side of the flap in a subfascial plane in a radial direction exploring both median nerve and main trunk of the radial artery (Fig. A2,3,4).

Adhesiolysis of the median nerve was done both from the superficial and deep surfaces leaving the nerve completely free with preserving the palmar cutaneous branch, internal neurolysis was done in all patients releasing the tethered epineurium (Fig. A5-8).

Distal perforators from the radial artery were identified and dissected from the intermuscular

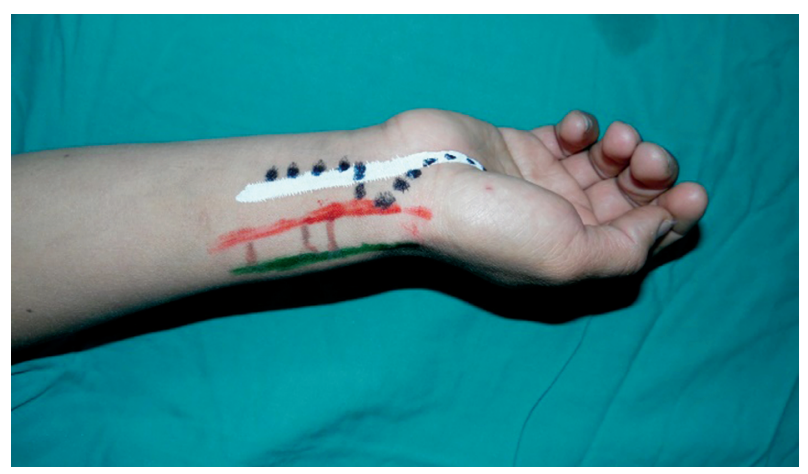

Fig. (A1) septum and selection of the largest perforator to raise the flap on with ligation of the remaining perforator (Fig. A9).

A suprafascial dissection was done from ulnar to radial direction with preserving only $1-2 \mathrm{~mm}$ beneath the dermis, dissection continued till the radial side of the flap is reached and then completing flap elevation preserving both cephalic vein and superficial radial nerve which were not included in the flap (Fig. A10).

The tourniquet was released then the viability of the flap was assessed and hemostasis was done, this is technical refinement of the originally described flap by sliding the flap underneath the median nerve without rotation. The flap was wrapped around the nerve to be sutured to the other edge of the flap creating a vascularized tube around the nerve (Fig. 11).

Further stitches were taken to the distal end of the flap to the remnants of the flexor retinaculum and between the proximal end of the flap and the muscles to maintain the length of the flap (Fig. A12).

Primary closure of the wound was done and the hand was put in a static wrist splint with allowing free fingers motion for 10 days (Fig. A13).

Patients were followed-up for one year postoperatively and all preoperative assessments were repeated and recorded, all data were expressed as mean \pm Standard deviation (SD). Statistics analysis of data was carried out by IBM® ${ }^{\circledR}$ SPSS $®$ Statistics Version 20 for Windows 7 Home Edition using Chi-Square Tests, $\chi^{2}$-tests. A $p$-value of $<0.05$ was considered statistically significant.

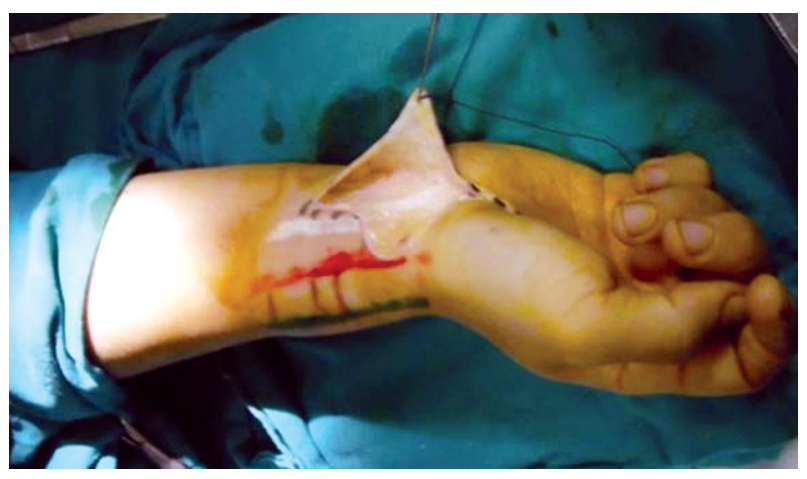

Fig. (A2) 

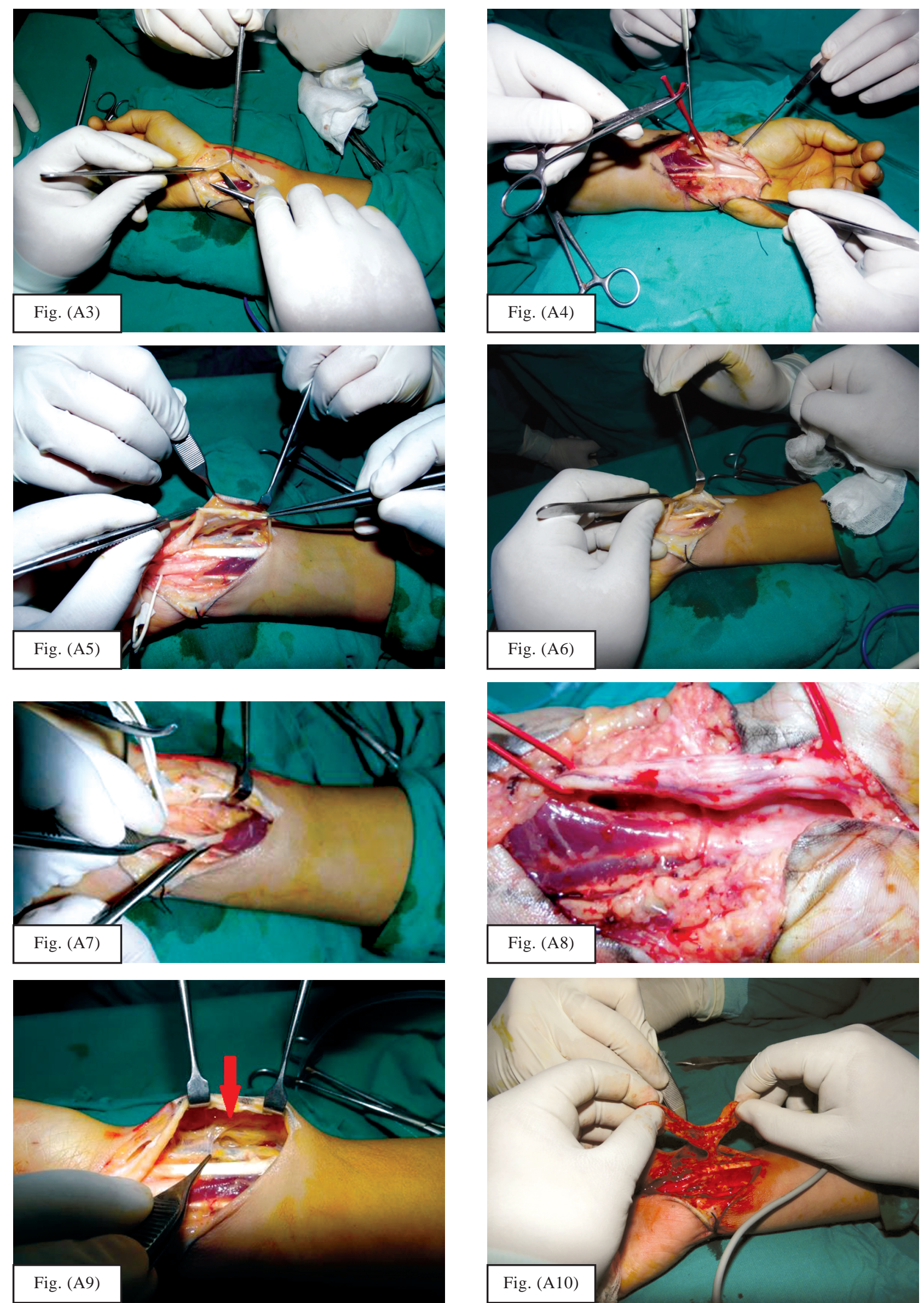

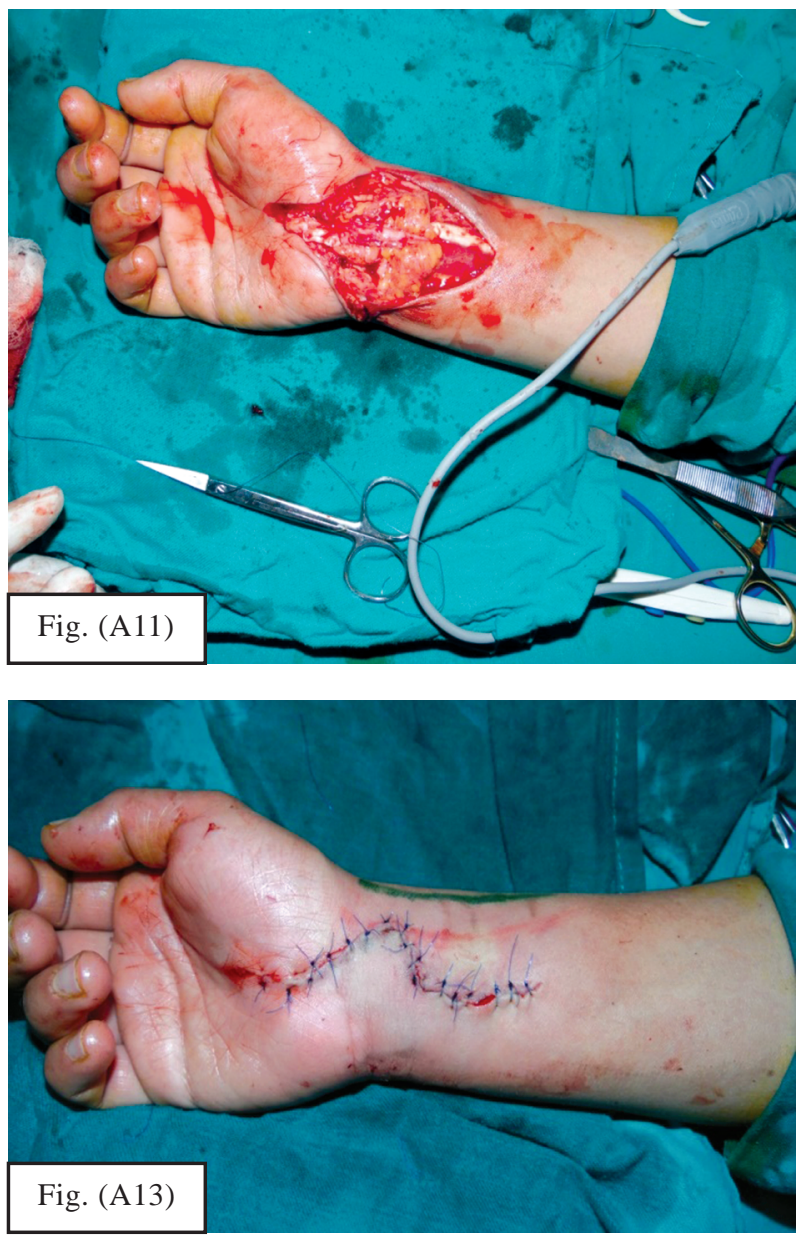

\section{RESULTS}

A total of fifteen patients underwent coverage of median nerve with adipofascial radial artery perforator flap. Three of them were males $(20 \%)$ and twelve were females $(80 \%)$. Their age range was 23-49 years (mean $36 \pm 11$ years), and time elapsed since the last operation was between $8.5 \pm$ 2.01 month.

The flap dimensions (length was between 9-14 $\mathrm{cm}$ and width was $3.5-5 \mathrm{~cm}$ ). Mean surface area of the flap was $32 \pm 13 \mathrm{~cm}^{2}$; the largest flap was $14 \mathrm{x}$ $5 \mathrm{~cm}$.

Number of distal perforators was two in eleven patients were found within $2 \mathrm{~cm}$ of the styloid process and three perforators existed in four patients. All of our patients, the flap was raised dependent on a single perforator.

Fourteen patients had -ve Tinel sign on the first dressing two days post operatively, one patient had persistent Tinel sign for one month postoperatively. The mean value of visual analoge scale decreased significantly from 9 preoperatively to

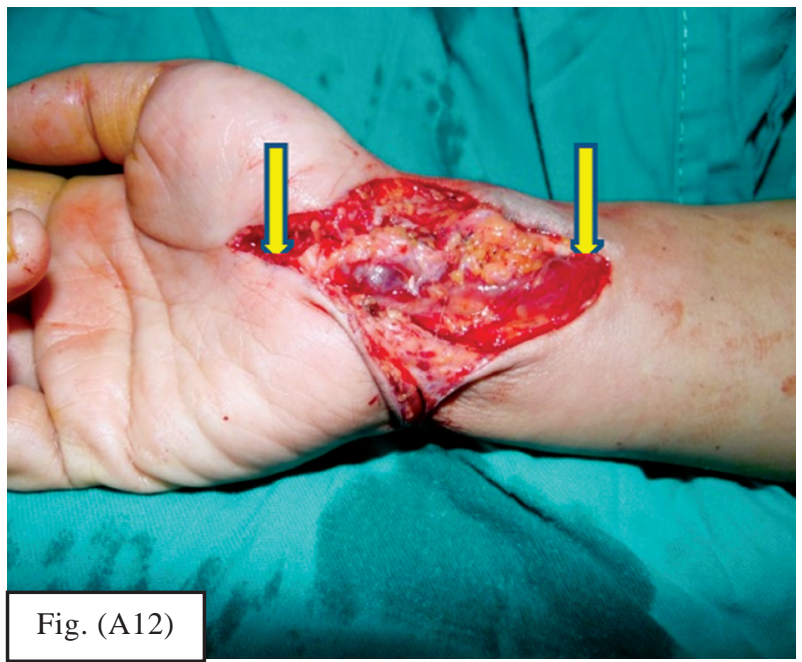

Fig. (A): A1: The median nerve was marked in white, proposed incision in dotted black. A2,3: Dissection begin in a subdermal direction leaving only 1 to $2 \mathrm{~mm}$ of subcutaneous fat and Elevation of the adipofascial flap over the median nerve. A4-8: Release of adhesion and Intra neural dissection. A9: Localization of the perforator the radial side of the flap was dissected. A10: The flap is now raised based on a single distal perforator $2 \mathrm{~cm}$ above the radial styloid process. A11: This is our technical refinement of the originally described flap by sliding the flap underneath the median nerve without rotation. A12: The distal part of the flap was sutured to the remnant of the flexor retinaculum and the proximal part sutured to flexor pollicis muscle to ensure complete coverage of the median nerve. A13: Primary closure with good colour of the defattened skin flaps.

1.2 at the end of follow-up period. Both motor and sensory latency were improved significantly towards normal value (Table 1), 2 point discrimination regain to near normal value, grip strength increased to about $20 \mathrm{~kg}$ and tip pinch test increased to about $7 \mathrm{~kg}$ (Table 1). Score of quick disabilities of the arm and shoulder (DASH score) improved from $53 \pm 12$ preoperatively to $31 \pm 7$. Sever affection in the compound action potential of abductor pollicis brevis was noted in four patients preoperatively with reappearance of normal compound action potential after one year.

Table (1): Results preoperatively and postoperatively.

\begin{tabular}{lll}
\hline & Preoperative & Postoperative \\
\hline VAS & 9 & 1.2 \\
Motor latency & $5.42 \pm 0.56$ & $3.6 \pm 0.4$ \\
Sensory latency & $4.59 \pm 0.72$ & $3.04 \pm 0.38$ \\
2 point discrimination & $11.1 \pm 0.2 \mathrm{~mm}$ & $5.1 \pm 0.1 \mathrm{~mm}$ \\
Grip strength & $12.7 \pm 2.4 \mathrm{~kg}$ & $19 \pm 3.9 \mathrm{~kg}$ \\
Tip pinch strength & $3.9 \pm 0.6 \mathrm{~kg}$ & $6.8 \pm 1.8 \mathrm{~kg}$ \\
\hline
\end{tabular}




\section{DISCUSSION}

Poor results were obtained following 2ry neurolysis. Multiple flaps was used to cover the neurolysed median nerve aiming to provide protection and good vascularity to the nerve as hypothenar fat bad, palmaris brevis and abductor digiti minimi muscle flaps [13]. Limitation of those flaps was their limited size, limited arc of rotation and coverage of the nerve from its palmar aspect only [14].

Reverse radial artery fascial flap was used to cover the neurolysed median nerve by Tham et al., [14] with great arc of rotation and large surface area with the problem of sacrificing the radial artery. The flap was then modified by koshima et al., to be adipofascial perforator flap based on the proximal perforators with rotation of the flap to cover the median nerve [15].

Tiengo et al., [12] in their anatomical study on 16 cadaver found more numerous distal perforator of the radial artery with smaller diameter than the proximal perforators however in our study the caliber of the distal perforator was the same or slightly larger than the proximal perforator.

Number of the distal perforator in this study was the same as Cyr et al., [6] anatomical study with presence of 2-3 perforators within $2 \mathrm{~cm}$ of the radial styloid process. In one case in our study a significant perforator was found distal to the styloid process.

However wrapping of median nerve by vascularized tissue is used in many researches by facial flaps of free tissue transfer $[\mathbf{1 , 1 7 , 1 8}]$. In this clinical series, the distal radial artery perforator adipofascial flap was as a tube to cover, protect the nerve, prevent adhesion and improve vascularity and nutrition around the median nerve. The vascularized wrapping allows coverage of long distance of nerve allows smooth gliding and prevents adhesion around the median nerve.

The improvement of pain and Tinel sign in this study are in concordance with other studies using fascial flaps $[\mathbf{1 9 , 2 0}]$. It has advantages over other fascial flaps and free tissue in mean of decrease bulkiness, donor site morbidity and radial artery harvesting. The vascularity of skin of distal forearm in this series was not affected by flap elevation, the wound closed primary without tension and wound healing occurred without complications.

\section{Conclusion:}

Distal radial artery perforator adipofascial tubed flap is very useful, easy to elevate flap to provide
360 degree protection of the median nerve with enough size to cover all the superficial part of the median nerve in the distal forearm. To our knowledge this is the 1 st clinical series to be done using the distal radial artery perforator adipofascial flap as a tube to cover, protect and prevent adhesion around the median nerve.

\section{REFERENCES}

1- Roberto A, Pierluigi Tos, Luigi T. and Massimo C.: Treatment of Painful Median Nerve Neuromas with Radial and Ulnar Artery Perforator Adipofascial Flaps. J. Hand Surg. Am., 39: 721-727, 2014.

2- Caroline A. Hundepool, Jetske Ultee, Tim H.J. Nijhuis, Peter Houpt and Steven E.R. Hovius: Prognostic factors for outcome after median, ulnar, and combined median and ulnar nerve injuries: A prospective study; Journal of Plastic, Reconstructive \& Aesthetic Surgery, 68: 1-8, 2015.

3- Hamdy A. El-Khatib: Tendofascial Island Flap Based on Distal Perforators of the Radial Artery: Anatomical and Clinical Approach; Plast. Reconstr. Surg., 113: 545-549, 2004.

4- Braun R.M., Rechnic M., Neill-Cage D.J. and Schorr R.T.: The retrograde fascial forearm flap: Surgical rationale, technique, and clinical application. J. Hand Surg. Am. 20 (6): 915-922, 1995.

5- Yang D., Morris S.F., Tang M. and Geddes C.: Reversed forearm island flap supplied by the septocutaneous perforator of the radial artery: Anatomical basis and clinical applications. Plast. Reconstr. Surg., 112 (4): 1012-1016, 2003.

6- Saint-Cyr M., Mujadzic M., Wong C., Hatef D., Lajoie A. and Rohrich R.J.: The radial artery pedicle perforator flap: Vascular analysis and clinical implications. Plast. Reconstr. Surg., 125 (5): 1469-1478, 2010.

7- Ho A.M. and Chang J.: Radial artery perforator flap. J. Hand Surg. Am., 35 (2): 308-311, 2010.

8- Weinzweig N., Chen L. and Chen Z.W.: The distally based radial forearm fasciosubcutaneous flap with preservation of the radial artery: An anatomic and clinical approach. Plast. Reconstr. Surg., 94 (5): 675- 684, 1994.

9- Onode E., Takamatsu K., Shintani K., et al.: Anatomical Origins of Radial Artery Perforators Evaluated Using Color Doppler Ultrasonography. J. Reconstr. Microsurg., 32 (8): 594-598, 2016.

10- Schaverien M. and Saint-Cyr M.: Suprafascial Compared With Subfascial Harvest of the Radial Forearm Flap: An Anatomic Study. J. Hand Surg. Am., 33 (1): 97-101, 2008.

11- Hekner D.D. and Roeling: TAP, Van Cann E.M. Perforator anatomy of the radial forearm free flap versus the ulnar forearm free flap for head and neck reconstruction. Int. J. Oral Maxillofac. Surg., 45 (8): 955-959, 2016.

12- Tiengo C., Macchi V., Porzionato A., et al.: The proximal radial artery perforator flap (PRAP-flap): An anatomical study for its use in elbow reconstruction. Surg. Radiol. Anat., 29 (3): 245-251, 2007. 
13- Tollestrup T., Berg C. and Netscher D.: Management of Distal Traumatic Median Nerve Painful Neuromas and of Recurrent Carpal Tunnel Syndrome: Hypothenar Fat Pad Flap. J. Hand Surg. Am., 35 (6): 1010-1014, 2010.

14- Tham S.K.Y., Ireland D.C.R., Riccio M. and Morrison W.A.: Reverse radial artery fascial flap: A treatment for the chronically scarred median nerve in recurrent carpal tunnel syndrome. J. Hand Surg. Am. 21 (5): 849-854, 1996.

15- Uemura T., Takamatsu K., Okada M., Ikeda M. and Nakamura H.: Radial artery perforator adiposal flap for coverage of the scarred median nerve. J. Plast. Reconstr. Aesthetic. Surg., 66 (7): 1019-1021, 2013.

16- Khan U., O'Brien M. and Pickford M.A.: Free radial forearm adipofascial flaps raised through limited incisions; British Journal of Plastic Surgery, 55: 412-415, 2002.

17- Mostafa M., Sherif El Shafie, Erin E. Coppola and John C. Elfar: Perforator-Based Radial Forearm Fascial Flap for Management of Recurrent Carpal Tunnel Syndrome. Journal of Hand Surgery, 38A: 2151-2158, 2013.
18- Zhang J., Zang M., Yu S., Xu L. and Liu Y.: Reconstruction of forearm soft tissue defects with radial artery perforatorpedicled propeller flaps. J. Plast. Reconstr. Aesthetic Surg., 68 (1): 125-126, 2015.

19- Dahlin L.B.., Lekholm C., Kardum P. and Holmberg J. Coverage of the median nerve with free and pedicle flaps for the treatment of recurrent severe carpal tunnel syndrome. Scand J. Plast. Reonstr. Surg. Hand Surg., 36 (3): 172-176, 2002.

20- Elliot D., Lloyd M., Hazari A., Sauerland S. and Anad P.: Relief of the pain of neuromas-in-continuity and scarred median and ulnar nerves in the distal forearm and wrist by neurolysis, wrapping in vascularised forearm fascial flaps and adjunctive procedures. J. Hand Surg. Eur., 35 (7): 575- 582, 2010.

21- London D.A., Stepan J.G., Boyer M.I. and Calfee R.P.: Performance characteristics of the verbal Quick DASH. J. Hand Surg. Am., 39 (1): 100-107, Jan 2014. 